\title{
Prevalence and Factors Associated High Blood Pressure among Women at the Market of Dantokpa in Benin in 2017
}

\section{Mama Cisse Ibrahim ${ }^{1}$, Alassani Adébayo ${ }^{*}$, Adjobimey Mènonli ${ }^{2}$, Alpha Bio Issifou Amadou1, Mikponhoue Rose ${ }^{2}$, Hinsou Antoine Vikkey², Ayelo Paul ${ }^{1}$}

${ }^{1}$ Departemental Teaching Hospital of Borgou, Parakou, Benin

${ }^{2}$ National Teaching Hospital, Cotonou, Benin

Email: *adebayoalassani@gmail.com

How to cite this paper: Ibrahim, M.C., Adébayo, A., Mènonli, A., Amadou, A.B.I., Rose, M., Vikkey, H.A. and Paul, A. (2020) Prevalence and Factors Associated High Blood Pressure among Women at the Market of Dantokpa in Benin in 2017. Occupational Diseases and Environmental Medicine, 8, 91-98.

https://doi.org/10.4236/odem.2020.83007

Received: May 3, 2020

Accepted: July 12, 2020

Published: July 15, 2020

Copyright $\odot 2020$ by author(s) and Scientific Research Publishing Inc. This work is licensed under the Creative Commons Attribution International License (CC BY 4.0).

http://creativecommons.org/licenses/by/4.0/ (c) (i) Open Access

\begin{abstract}
Introduction: Cardiovascular disease (CVD) is the leading cause of death worldwide. Among these CVDs, high blood pressure (hypertension) is the main one. The purpose of this study is to investigate the prevalence and factors associated with hypertension in women in the market of Dantokpa. Study Method: This is a cross-sectional, descriptive and analytical survey undertaken on women selling in the Dantokpa market. The dependent variable is hypertension. Data analysis was done using Epi data 3.1 software. Results: A total of 255 women were enrolled in the study. The average age was $41.6 \pm 12.13$ years with extremes of 18 and 84 years. Among women, 114 (34\%) were suffering from hypertension. The factors associated with hypertension in women in the Dantokpa market were above 40 years old, educated women, physical inactivity, family history of hypertension, salty food. Conclusion: At the end of this study, it appears that the prevalence of hypertension in women in the Dantokpa market is higher than that of the general female population. Therapeutic and preventive measures are necessary.
\end{abstract}

\section{Keywords}

High Blood Pressure, Prevalence, Associated Factors, Dantokpa, Benin

\section{Introduction}

Non-communicable diseases are a global public health problem, especially in developing countries. It is a group of diseases affecting subjects above age 70 . 
Young people are increasingly affected and they are responsible for 15 million premature deaths (subjects from 30 to 69 years) among which $80 \%$ occur in developing countries. Anyway, action is needed because $90 \%$ of deaths from non-communicable diseases will occur in these non-developed countries by 2030 [1]. Among these non-communicable diseases, hypertension (hypertension) is one of the most important. Estimation from the World Health Organization has shown that $40 \%$ of adults over the age of 25 are living with hypertension [2]. It is the leading cause of cardiovascular mortality worldwide [3] with 7.1 million deaths every year [4]. Hypertension is a major concern because of its frequency but also of its cardiac, neurological and renal complications [5] with $50 \%$ of deaths due to cerebrovascular accidents and $45 \%$ of deaths due to cardiac diseases [6]. In gynecologic department, hypertension is the main cause of maternal and fetal death [7]. The risk factors for hypertension are threefold: lifestyle, metabolic and biochemical. Lifestyle habits include alcohol, tobacco, poor nutrition and physical activity; metabolic factors combine overweight, obesity, diabetes; biochemical factors are concerned with hypercholesterolemia and hypertriglyceridemia [8] [9]. Hypertension is well studied in Benin. According to the 2015 STEPS survey [10], its prevalence is $25.9 \%$. However, little data exist on its prevalence among women in the Dantokpa market who contribute enormously to the economic activity of the country. This is a group of women at risk due to their activity that forces them to be sedentary all day. The results of this study will determine the prevalence of hypertension and identify the factors associated with it in order to improve the health status in this social group.

\section{Methodology}

- Study setting: the study took place in Dantokpa market, the largest market in Benin located in the Littoral department; women in this market contribute enormously to the economic activity of the country.

- Study design and period: this was a descriptive and analytical cross-sectional study covering the period from June 18, 2017 to September 18, 2017.

- Study population: it consists of women vendors of the Dantokpa market, aged at least 18 years and who have given their consent to participate in the study. Women who were unable to respond and who were pregnant were not included in the study.

- Sampling method: the sample size was calculated using Schwartz's formula [8]. A comprehensive census of women has been made for this purpose.

$$
n=\frac{\varepsilon \alpha^{2} p q}{i^{2}}
$$

$n=$ size of study population.

$p=20.9 \%$ is hypertension prevalence in women according to STEPS 2015 [10] in Littoral department in Benin.

$q=1-p=79.1 \%$ is non hypertension prevalence in women according STEPS 2015 [10] in Littoral department in Benin. 
$\varepsilon a^{2}=1.96^{2}$ is error risk.

$i=0.05$ is the precision.

$n=(1.96)^{2} \times 0.209 \times 0.791 /(0.05)^{2}=254.035$ round off 255 .

- Variables: the dependent variable studied is overweight women with hypertension. Blood pressure was measured in all participants on their both arms after 10 minutes of rest. Only the highest value was considered for assessment of hypertension. Women with systolic blood pressure (SBP) above or equal to $140 \mathrm{~mm} \mathrm{Hg}$ with a diastolic blood pressure (DBP) above or equal to $90 \mathrm{mmHg}$ including those with past history of hypertensive were considered to have hypertension condition. Women with hypertension were treated and advice was given in how to manage balanced diet, physical activity and medication, as appropriate. The independent variables are socio-demographic data and lifestyle. Women practicing less than 30 minutes physical activity for instance walking per day 5 times per week were considered sedentary. A waist measurement greater than or equal to $80 \mathrm{~cm}$ is considered to be above the threshold of normal value.

- Data collection: data collection was done by direct interview with enrolled women. The blood pressure and anthropometric data were measured after each interview conducted. A questionnaire and other appropriate translation tools were used for those who are not speaking french.

- Data entry and analysis: the data were entered using the EPIDATA version 3.1 software after checking each file, they were analyzed using the EPIINFO version 7, STATA 11 and Alimentheque software. A p-value of less than 0.05 was considered to be significant.

- Ethical consideration and approval: Throughout the survey, anonymity, privacy and confidentiality of the information gathered was emphasized and upheld. Data collected during this study were stored in secured condition. Any information that was obtained in this study that can be identified remained confidential and was disclosed with the participant's consent or as required by law.

- Informed consent: before commencing the survey, consent is obtained from every participant, after explaining the purpose of the research, the nature of their requested participation, and an opportunity for them to ask questions. Participation is completely voluntary, and the participants were informed of their alternatives to participation, including their right to refuse or withdraw participation at any time during the study without penalty.

\section{Results}

A total of 255 women were enrolled in the study. The average age is $41.6 \pm 12.13$ years with an extreme of 18 and 84 years. Women under the age of 40 represent $44 \%$ of the study population. A Proportion of married women was (79\%), followed by educated (73\%), those having a high waist (89\%), consuming frozen food $(96 \%)$ or consuming salty (96\%) were observed. Also in 5 women almost 3 
(58\%) are active, 3 in 10 women (29\%) have a family history of hypertension (Table 1).

Among women, 114 (34\%) suffer from hypertension. Of these, 16 (14\%) are newly screened. The average SBP is $128.67 \pm 26.57 \mathrm{mmHg}$ with a minimum of $110 \mathrm{mmHg}$ and a maximum of $201 \mathrm{mmHg}$. The average of the DBP is $69.1 \pm$ $25.26 \mathrm{mmHg}$ with a minimum of $59 \mathrm{mmHg}$ and a maximum of $99 \mathrm{mmHg}$ (Table 1).

In univariate analysis, the factors associated with hypertension in women in the market of Dantokpa are age $>40$ years, educated women, family history of hypertension, sedentary lifestyle, salty food, overweight and a high waistline (Table 2).

In multivariate analysis, the factors associated with overweight among women in the Dantokpa market are age $>40$ years, educated women, physical inactivity, family history of hypertension, salty food (Table 3 ).

\section{Discussion}

The present study, is one of the few studies focusing on hypertension among women on the Dantokpa market, had adopted an acceptable methodology through a transversal, descriptive and analytical study. Identifying the factors associated with using a logistic regression model for reliable results.

Table 1. General characteristics of the study population $(\mathrm{n}=255)$.

\begin{tabular}{|c|c|c|c|}
\hline Variables & n (\%) & Variables & $\mathrm{n}(\%)$ \\
\hline Age (years) & \multicolumn{3}{|c|}{ Marital status } \\
\hline$\leq 40$ & $148(44)$ & Married & $264(79)$ \\
\hline Physical activity level & \multicolumn{3}{|c|}{ Body mass index } \\
\hline Active & $196(58)$ & $<25 \mathrm{~kg} / \mathrm{m}^{2}$ & $44(13)$ \\
\hline Education level & \multicolumn{3}{|c|}{ Family history of hypertension } \\
\hline None & $92(27)$ & Yes & $98(29)$ \\
\hline Waist circumference & \multicolumn{3}{|c|}{ Recent weight gain } \\
\hline High & $299(89)$ & Yes & $136(40)$ \\
\hline Energy intake & \multicolumn{3}{|c|}{ Lipid intake } \\
\hline High energy intake & $136(40)$ & High fat intake & $84(25)$ \\
\hline Consumption of fruits and ve & \multicolumn{3}{|c|}{ Consumption of frozen food } \\
\hline$<5$ servings & $326(97)$ & Yes & $323(96)$ \\
\hline Salty food & \multicolumn{3}{|c|}{ Adding salt when cooking } \\
\hline Yes & $54(16)$ & Yes & $323(96)$ \\
\hline Use of canned food & \multicolumn{3}{|c|}{ Alcohol consumption } \\
\hline Yes & $276(82)$ & Yes & $215(64)$ \\
\hline Blood pressure & \multicolumn{3}{|c|}{ Newly screened hypertension } \\
\hline Hypertension & $114(34)$ & Yes & $16(14)$ \\
\hline
\end{tabular}


Table 2. Factors associated with high blood pressure in women of Dantokpa (univariate analysis).

\begin{tabular}{cccc}
\hline & & Hypertension (\%) & P \\
\hline Age (years) & $\leq 40$ & 21.62 & 0.003 \\
Education level & $>40$ & 43.62 & \\
Family history of hypertension & None & 17.39 & 0.005 \\
Educated & 40.16 & 0.006 \\
Physical activity level & Yes & 46.27 & \\
Salty food & No & 25.74 & 0.04 \\
& No active & 42.86 & \\
Body mass index & Active & 27.55 & 0.006 \\
& Yes & 38.30 & \\
& No & 11.11 & 0.029 \\
Waist circumference & $<25 \mathrm{~kg} / \mathrm{m}^{2}$ & 15.38 & \\
& $\geq 25 \mathrm{~kg} / \mathrm{m}^{2}$ & 37.32 & \\
& Normal $(<80 \mathrm{~cm})$ & 11.11 & \\
\hline
\end{tabular}

Table 3. Factors associated with high blood pressure in women of Dantokpa (multivariate analysis).

\begin{tabular}{|c|c|c|c|}
\hline & & OR (IC à 95\%) & $\mathrm{p}$ \\
\hline \multirow[t]{2}{*}{ Salty food } & No & 1 & \multirow{2}{*}{0.01} \\
\hline & Yes & $0.14[0.03 ; 0.60]$ & \\
\hline \multirow[t]{2}{*}{ Physical activity level } & Active & 1 & \multirow{2}{*}{0.03} \\
\hline & No active & $2.07[1.07 ; 3.99]$ & \\
\hline \multirow[t]{2}{*}{ Family history of hypertension } & No & 1 & \multirow{2}{*}{0.01} \\
\hline & Yes & $2.32[1.20 ; 4.50]$ & \\
\hline \multirow[t]{2}{*}{ Education level } & None & 1 & \multirow{2}{*}{0.01} \\
\hline & Educated & $3.32[1.29 ; 8.53]$ & \\
\hline \multirow[t]{2}{*}{ Age (years) } & $\leq 40$ & 1 & \multirow{2}{*}{$<0.001$} \\
\hline & $>40$ & $5.27[2.25 ; 12.34]$ & \\
\hline
\end{tabular}

At the end of this study, the prevalence of hypertension in this population is $34 \%$. This prevalence is higher than that of $24.3 \%$ reported in the general population among women in the 2015 STEPS survey [10]. This higher prevalence could be explained by the profession (selling at market) of these women which forces them to remain sedentary all day; being sedentary is considered a risk factor for non-communicable diseases like hypertension [11]. Similar prevalence rates of $31 \%$ and $35.5 \%$ were reported among women by Drame [12] in the region of Mono, Couffo and Donga in Benin respectively and by Awuah [6] in 
Ghana respectively. Among hypertensive women, $14 \%$ are newly screened so their pathology is unknown with an increased risk of developing complications. In Drame's study [12], 6\% of women did not know they had hypertension. It is therefore a pathology that should be screened because most of the symptoms are absent at the beginning stage. This high prevalence of hypertension needs more research on the factors associated with it.

In multivariate analysis, the factors associated with overweight among women in the Dantokpa market are age above 40 years, educated women, physical inactivity, family history of hypertension, consuming salty food.

In the studies of Afsargharehbagh, Tinmou and Pierre [13] [14] [15], advanced age is a factor associated with hypertension confirming the association found in the present study. Women with higher education were more at risk of hypertension. Bosu [16] reported similar association. Indeed, the women of the Dantokpa market with a higher level of education were those who had more financial property. They do less movement which promotes physical inactivity and a sedentary lifestyle. These last two situations are factors favoring hypertension [12].

The association between physical inactivity and hypertension found in the present study was also reported by Leung [17] in Canada. To control this risk factor, the creation of a physical activity center within the market combine with education of these women may be the way to contribute to preventing this condition.

The family history of hypertension is associated with hypertension. Youseff [18] and Ondimu [4] reported the same associations. It is an avoidable risk factor by adopting a lifestyle that promotes a healthy and balanced diet and regular physical activity.

Eating salty food is associated with hypertension. In fact, the salt promotes water retention in the body responsible for the increase in blood volume and therefore an increase in blood pressure. Drame [12] and Provido [9] reported the same associations.

\section{Conclusion}

At the end of this study, it appears that the prevalence of hypertension in women in the Dantokpa market is higher than that of the general female population. Therapeutic and preventive measures are necessary and must be taken into account for changes in lifestyle through regular physical activity and the reduction of salt consumption. An emphasis that will be placed on older women, with a family history of hypertension or educated.

\section{Conflicts of Interest}

The authors declare no conflicts of interest regarding the publication of this paper.

\section{References}

[1] Amanyire, J., Tumwebaze, M., Mugisha, M.K. and Bright, L.W. (2019) Prevalence 
and Risk Factors for Hypertension, Diabetes and Obesity among Lecturers and Support Staff of Bishop Stuart University in Mbarara, Uganda. Open Journal of Applied Sciences, 9, 126-137. https://doi.org/10.4236/ojapps.2019.93012

[2] Chelo, D., Mah, E.M., Chiabi, E.N., Chiabi, A. and Ndombo, P. (2019) Prevalence and Factors Associated with Hypertension in Primary School Children, in the Centre Region of Cameroon. Translational Pediatrics, 8, 391-397.

https://doi.org/10.21037/tp.2019.03.02

[3] Lamelas, P., Diaz, R., Orlandini, A., Avezum, A., Oliveira, G., Mattos, A., et al. (2019) Prevalence, Awareness, Treatment and Control of Hypertension in Rural and Urban Communities in Latin American Countries. Journal of Hypertension, 37, 1-9. https://doi.org/10.1097/HJH.0000000000002108

[4] Ondimu, D.O., Kikuvi, G.M. and Otieno, W.N. (2019) Risk Factors for Hypertension among Young Adults (18-35) Years Attending in Tenwek Mission Hospital, Bomet County, Kenya in 2018. Pan African Medical Journal, 33, 210.

https://doi.org/10.11604/pamj.2019.33.210.18407

[5] Gregolin, C.S., Souza, S.L., Oliveira, R., Lourenço, F.J., Nascimento, A.F. and Sugizaki, M.M. (2019) Prevalence of Hypertension and Risk Factors in Sinop City (Mato Grosso/Brazil). Scientific Electronic Archives, 12, 1-9. https://doi.org/10.36560/1262019973

[6] Awuah, R.B., Aikins, A., Dodoo, F.N., Meeks, K., Beune, E., Klipstein-Grobusch, K., et al. (2019) Psychosocial Factors and Hypertension Prevalence among Ghanaians in Ghana and Ghanaian Migrants in Europe: The RODAM Study. Health Psychology Open, 6, 2055102919885752. https://doi.org/10.1177/2055102919885752

[7] Laine, K., Murzakanova, G. and Sole, K.B. (2019) Prevalence and Risk of Pre-Eclampsia and Gestational Hypertension in Twin Pregnancies: A Population-Based Register Study. BMJ Open, 9, e029908.

https://doi.org/10.1136/bmjopen-2019-029908

[8] Vijayakarthikeyan, M. and Muthulakshmi, M. (2020) Determinants of Hypertension in a Rural Area of Kancheepuram District, Tamilnadu. Global Journal of Medical Research, 10, 47-57. https://doi.org/10.34257/GJMRBVOL20IS1PG47

[9] Provido, S., Abris, G.P., Hong, S., Yu, S.H., Lee, C.B. and Lee, J.E. (2020) Association of Fried Food Intake with Prehypertension and Hypertension: The Filipino Women's Diet and Health Study. Nutrition Research and Practice, 14, 76-84. https://doi.org/10.4162/nrp.2020.14.1.76

[10] STEPS Study, Prevalence of Hypertension in Population, Republic of Benin, 2015.

[11] Hansen, B.H., Kolle, E., Steen-Johannessen, J., Dalene, K.E., Ekelund, U. and Anderssen, S.A. (2019) Monitoring Population Levels of Physical Activity and Sedentary Time in Norway across the Lifespan. Scandinavian Journal of Medicine \& Science in Sports, 29, 105-112. https://doi.org/10.1111/sms.13314

[12] Dramé, M., Houehanou, C., Sogbohossou, P., Paré, R., Ekambi, A., MizéhounAdissoda, C., et al. (2018) Determinants of High Blood Pressure and Quality of Management in Three Regions of Benin. Open Journal of Epidemiology, 8, 14-28. https://doi.org/10.4236/ojepi.2018.81002

[13] Afsargharehbagh, R., Rezaie-Keikhaie, K., Rafiemanesh, H., Balouchi, A., Bouya, S. and Dehghan, D. (2019) Hypertension and Pre-Hypertension among Iranian Adults Population: A Meta-Analysis of Prevalence, Awareness, Treatment, and Control. Current Hypertension Reports, 21, 27-39. https://doi.org/10.1007/s11906-019-0933-z

[14] Timnou, T., Boombhi, J., Simeni Njonnou, S.R., Jingi, A.M., Nkem Efon, K., Bâ, H., 
et al. (2019) Prevalence of Hypertension and Associated Risk Factors among a Group of Prisoners in Yaounde Central Prison: A Cross-Sectional Study. Journal of Xiangya Medicine, 1-8. https://doi.org/10.1155/2020/5016327

[15] Pierre, S., Seo, G. and Rivera, V.R. (2019) Prevalence of Hypertension and Cardiovascular Risk Factors among Long-Term AIDS Survivors: A Report from the Field. Journal of Clinical Hypertension, 21, 1558-1566. https://doi.org/10.1111/jch.13663

[16] Bosu, W.K. (2016) Determinants of Mean Blood Pressure and Hypertension among Workers in West Africa. International Journal of Hypertension, 2016, Article ID: 3192149. https://doi.org/10.1155/2016/3192149

[17] Leung, A., Bushnik, T., Hennessy, D., McAlister, F. and Manuel, D. (2019) Risk Factors for Hypertension in Canada. Health Reports, 30, 3-13.

[18] Yousef, K., Anwar, B., Hashem, J., Sukaina, R.I., Mohammed, E., Dana, H., et al. (2019) Hypertension in Jordan: Prevalence, Awareness, Control, and Its Associated Factors. Hindawi International Journal of Hypertension, 2019, Article ID: 3210617. https://doi.org/10.1155/2019/3210617 